\title{
A New Empirical Correlation for Estimation of EBF Steel Frame Behavior Factor under Near-Fault Earthquakes Using the Genetic Algorithm
}

\author{
Seyed Abdonnabi Razavi $\mathbb{D}^{1},{ }^{1}$ Navid Siahpolo ${ }^{(D)},{ }^{1,2}$ and Mehdi Mahdavi Adeli ${ }^{1}{ }^{1}$ \\ ${ }^{1}$ Department of Civil Engineering, Ahvaz Branch, Islamic Azad University, Ahvaz, Iran \\ ${ }^{2}$ Department of Civil Engineering, Institute for Higher Education ACECR, Khouzestan, Iran \\ Correspondence should be addressed to Navid Siahpolo; n.siahpolo@gmail.com
}

Received 21 June 2020; Revised 25 August 2020; Accepted 15 October 2020; Published 4 November 2020

Academic Editor: Claudio Mazzotti

Copyright (C) 2020 Seyed Abdonnabi Razavi et al. This is an open access article distributed under the Creative Commons Attribution License, which permits unrestricted use, distribution, and reproduction in any medium, provided the original work is properly cited.

\begin{abstract}
The most important feature of the behavior factor is that it allows the structural designer to be able to evaluate the structural seismic demand, using an elastic analysis, based on force-based principles quickly. In most seismic codes, this coefficient is merely dependent on the type of lateral resistance system and is introduced with a fixed number. However, there is a relationship between the behavior factor, ductility (performance level), structural geometric properties, and type of earthquake (near and far). In this paper, a new and accurate correlation is attempted to predict the behavior factor $(q)$ of EBF steel frames, under near-fault earthquakes, using the genetic algorithm (GA). For this purpose, a databank consisting of 12960 data is created. To establish different geometrical properties of models, 3-, 6-, 9-, 12-, 15, and 20- story steel EBF frames were considered with 3 different types of link beam, 3 different types of column stiffness, and 3 different types of brace slenderness. Using nonlinear time history under 20 near-fault earthquake, all models were analyzed to reach 4 different performance levels. 6769 data were used as GA training data. Moreover, to validate the correlation, 2257 data were used as test data for calculating mean squared error (MSE) and correlation coefficient $(R)$ between the predicted values of $(q)$ and the real values. In addition, the MSE and $R$ were calculated for correlation in the train and test data. Also, the comparison of the response of maximum inelastic displacement of 5 stories EBF from the proposed correlation and the mean inelastic time-history analysis confirms the accuracy of the estimate relationship.
\end{abstract}

\section{Introduction}

One of the prevalent methods for building seismic design is the force-based design (FBD) method which is used in common codes such as Eurocode 8 [1]. In this method, seismic forces are used to design of structures under lifesafety performance level, using a fixed behavior factor $(R$ or $q)$. In the FBD method, the maximum displacement and nonlinear interstory drift ratio can be obtained by multiplying the elastic values by the behavior factor $R$. This method assumes that the displacement equivalent rule which exists for SDOF (single degree of freedom) structures is also applicable to MDOF (multidegree of freedom) structures. The coefficient multiplied by the maximum displacement and the interstory drift ratio indicates the fact that the main drawback to the FBD method is that it assumes the displacement and the interstory drift ratio profile remains constant at height during seismic excitation. For reinforced concrete structures, Shimazaki et al. defined a range for $R$ and $T$ where the equivalent rule of displacement is established [2]. Lepage, developed the Shimazaki study and proposed a more accurate method to calculate the maximum seismic drift [3]. Many studies show that applying the equivalent displacement role can lead to overestimated of interstory drifts, which is unacceptable [4-8]. Another point is that the maximum displacement and interstory drift profiles change drastically from the elastic to the inelastic phase of the structural behavior. Castiglioni and Zambrano proposed a behavior factor using the cumulative damage index [9]. For this purpose, a set of elastic time-history 
analyses was used and the results obtained good agreement with those of the previous studies. Because of its simplicity in nonlinear analysis and avoidance of time consumption, the behavior factor obtained from linear analysis can cover a wider range of performance goals and is in good agreement with different levels of structure damage [9].

There are different definitions for the behavior factor. On the one hand, the behavior factor, $R$, corresponds to the definition given in FEMA440 [10]. In fact, the coefficient $R$ is the ratio of the elastic spectral acceleration corresponding to the fundamental period obtained from the pushover analysis. In another definition what is defined as the coefficient $R$ is the ratio of the elastic base shear to the inelastic base shear, both derived from structural time-history analysis. A unique feature of using common design principles allows the designer to achieve a rapid assessment of the seismic needs of existing buildings.

Previous research has been conducted to estimate the seismic needs of steel structures by researchers. Karavasilis et al. introduced a simple procedure to estimate drift and ductility demands of regular MRF buildings subjected to ordinary (i.e., without near-fault effects) ground motions. Given the strength reduction (or behavior) factor, the procedure provides reliable estimates of the maximum roof displacement, the maximum interstory drift ratio, and the maximum rotation ductility along the height of the structure. Structural characteristics, such as the number of stories and the beam-to-column stiffness ratio, are used to create the data bank in their study. The derivation of the proposed relations has been done based on the regression analysis of the results of nonlinear time-history analyses [11]. In another study, more than 100 regular multistorey $X$-braced steel frames were subjected to the 30 ordinary ground motions. A databank using the parameters such as number of stories, period of vibration, brace slenderness ratio, and column stiffness has been created in order to derive a simple formula which reflects the influences of the parameters on drift and ductility demands of $X$-braced steel structures. Hence, nonlinear regression analysis was employed to provide reliable estimates of the maximum roof displacement, the maximum interstory drift ratio, and the behavior factor [12]. Following this, approximate formulae for the estimation of lateral displacements at first yielding of plane steel frames under seismic excitations were provided for use in a performance-based seismic design by Dimopoulos et al. [13]. These formulae were also functions of the geometrical and design properties of the frames and derived on the basis of seismic response of 36 moment-resisting and $36 x$-braced plane steel frames, under 84 ordinary seismic ground motions. Moreover, Tzimas et al. [14] established a response databank and then utilized it for the development of empirical formulae providing the behavior factor as a function of the geometrical and dynamic characteristics of the $3 \mathrm{D}$ steel moment-resisting frame buildings. Consideration of higher mode (HM) and multidegree of freedom (MDOF) effects in extracting the $R$ factor was studied by Siahpolo et al. [15]. They created almost 1764 nonlinear dynamic analysis of 2D-frames under 30 ordinary and near-field earthquakes. Finally, a simplified practical expression was derived to estimate the required coefficients.
The experience of earlier earthquakes confirms that the structural responses enter to the nonlinear area, depending on the severity and content of the earthquake. Evaluation of the nonlinear responses shows that the base shear force demands are reduced in this case. The reduction in the reaction force and its conversion to the inelastic base shear force is defined in many seismic codes with a behavior factor (resistance reduction coefficient). These coefficients are generally obtained from empirical studies. The task of these coefficients is to consider all the nonlinear effects of the structure [16]. The major drawback to these coefficients is that it is assumed to be constant for structures with different performance levels and cannot provide a good picture of the nonlinearity levels of the structure and its components. For example, if the behavior factor of the structure is lower than its actual value, the forces applied to it are more likely to be considered and can lead to noneconomic design. Conversely, if the chosen behavior factor is greater than its actual value, the base shear force is less than the real value. In this case, it seems that, as the structure enters to the inelastic region, the deformation demands of the members become greater than the structure strength, thereafter damage to the structure occurs. Therefore, one of the differentiating aspects of the present study is the consideration of different performance levels in the input data bank for more accurate estimation of the relationship.

It is clear that, in the vicinity of active faults, ground motion is strongly influenced by fault mechanism, direction of fault rupture (i.e., forward directivity), and static permanent deformation at fault location known as fling-step movements. Thus, near-fault earthquake parameters cause a significant amount of fault rupture energy to appear as a pulse-type excitation with a long period. This is one of the most important aspects of distinguishing near-and far-fault earthquakes. Earth motion has such a pulse-type nature that it often appears at the beginning of the accelerometer and tends to extend the long period of the acceleration response spectrum. In this case, the structure damps a considerable amount of earthquake energy with a small number of disturbances over a large range and imposes considerable structural demands. Finally, the risk of brittle failure increased in structural elements with poorly executed details. The determinant effects of such phenomena were observed during the earthquake of Arzakan (1992), Landers (1992), Northridge (1994), Kobe (1995), Kochi (1999), Davies, and Chi-Chi.

Krawinkler et al. (1996) showed that the structural response is very sensitive to the acceleration pulse continuity by evaluating the steel moment frame due to the near-fault record [17]. Other observations showed that the main response of structures due to near-fault earthquake with fling-step effects (permanent displacement at strike-parallel direction of a strike-slip fault) was obtained at the first mode, and wavelike vibrations without the fling-effect causing main response of structure wereobtained at higher modes of the structures [18]. Gerami et al. (2013) studied steel moment-resisting frames under near-fault earthquakes with pulse velocities greater than $0.70 \mathrm{~s}$ and showed that the effects of forward directivity increased the global and local demands about 1.1-2.6 and 
1.2-3.5 times, respectively [19]. Also, Mashayekhi et al. (2019) illustrate that the interstory drift angle of structures under near-fault earthquakes with forward directivity effect is greater than far-fault earthquakes for about $30-50 \%$ of structure height in upper stories [20].

On the other hand, valuable research has been recently done on the improvement and effectiveness of steel structure design relationships using artificial intelligence algorithms, especially genetic algorithms. Prendes-Gero et al. evaluated the capability of GA algorithms with three different building codes (Spanish, European, and American). Finally, it has found that the results of the optimization show the heaviest structures with the American code and the lightest structures with the European code [21]. In another study, genetic algorithm was implemented to optimize a plane steel truss structure under point loadings. The genetic algorithm was developed in the MATLAB [22] software, and the optimized truss structure gotten from the algorithm was analyzed and designed under dead and imposed loadings to compare and determine the percentage weight reduction and check the feasibility of the optimized truss structure. The result has shown that the weight of the original truss gave a total weight of $5970.723496 \mathrm{~kg}$, while the weight of the optimized truss gave a total weight of $3147.1994 \mathrm{~kg}$ showing a weight reduction of about 52\% [23]. Baradaran et al. applied an improved genetic algorithm for optimal design of planar steel frames [24]. They showed that using the proposed method reduces the volume of computations and increases the rate of convergence, thus allowing access to frame designs with nearoptimal weights in only a few iterations. Seismic optimum design of steel structures uses gradient-based and genetic algorithm methods [25]. They applied MATLAB-based computer program to optimize low-consumption, medium, and relatively long steel frames without braces.

This article proposes a simple expression for estimating of behavior factor of the EBFs. These formulae are expressed based on geometrical characteristics of EBFs and are obtained based on parametric study including numerous nonlinear time-history analyses of $162 \mathrm{EBFs}$ with 4 performance levels under 20 near-fault ground motions. The considered geometrical characteristics include the number of stories, the brace slenderness, the stiffness of the columns, and the ratio of the link beam length to the total length of the beam. For this purpose, it is necessary to prepare a large database of studies of a considerable number of frames with an eccentrically braced frame system, using nonlinear dynamic analysis. A total of 12960 nonlinear analyzes were performed on the basis of a platform of IDA (incremental dynamic analysis) to create a database containing a wide range of relevant data. Nonlinear regression is used to derive a relationship to reasonably estimate of structural demands without consuming time and complex analysis. Subsequently, genetic optimization algorithm is used to estimate the correlation of behavior factor. It can be perceived that outcomes of the proposed patterns are in good agreement with the exact results of nonlinear time-history analyses. The main emphasis is on introducing of the potential of the proposed relationships to fit them into the framework of design methods based on elastic analysis. In this process, for a given behavior factor, $R$, the presented relationships can provide the designer with an acceptable estimate of the maximum roof displacement, the maximum interstory drift, and other structural demands.

\section{Genetic Algorithm}

A genetic algorithm encodes a potential solution to a problem (the phenotype) in a chromosome-like data structure called the genotype or genome. The canonical genetic algorithm has used binary strings to represent chromosomes [26]. Traditionally, GA works on a population consisting of some solutions where the population size (popsize) is the number of solutions. Each solution is called individual. Each individual solution has a chromosome. The gene is the basic unit of information that adopts a binary value $(0 / 1)$. In the method, each one of the decision variables can have a rank of possible different solutions, which is represented with an alphanumerical variable.

A chromosome is composed of genes. A genetic algorithm creates an initial population of (typically random) genomes, which are materialized as phenotypes and evaluated on the basis of some fitness function, to measure the suitability of the solution generated by GA with the problem. Those genomes that represent better solutions to the problem at hand have given opportunities to "reproduce," producing genomes for the next generation. Genomes also undergo mutation in order to ensure genetic diversity from one population to the next (analogous to biological mutation) [27]. The result of the fitness function is the fitness value representing the quality of the solution. The higher the fitness value the higher the quality the solution. Some chromosomes in the population will mate through a process called crossover, thus producing new chromosomes named offspring whose gene composition is the combination of its parents. Selection of the best individuals based on their quality is applied to generate what is called a mating pool where the higher quality individual has higher probability of being selected in the mating pool. A fitness function should possess the following characteristics:

(i) The fitness function should be sufficiently fast to compute

(ii) It must quantitatively measure how fit a given solution is or how fit individuals can be produced from the given solution.

After several generations, the chromosomes value will converge to a certain value which is the best solution for the problem [27]. Figure 1 shows the flowchart of the genetic algorithm.

The GA could be used for solving both constrained and unconstrained optimization problems [29]. Furthermore, it can be applied to solve a variety of optimizations of problems that are not well suited for standard optimization algorithms (especially, problems in which the objective function is highly nonlinear).

In this paper, GA is applied to minimize the objective function to improve the accuracy of the proposed correlation. The proposed correlation is described in Section 5. 


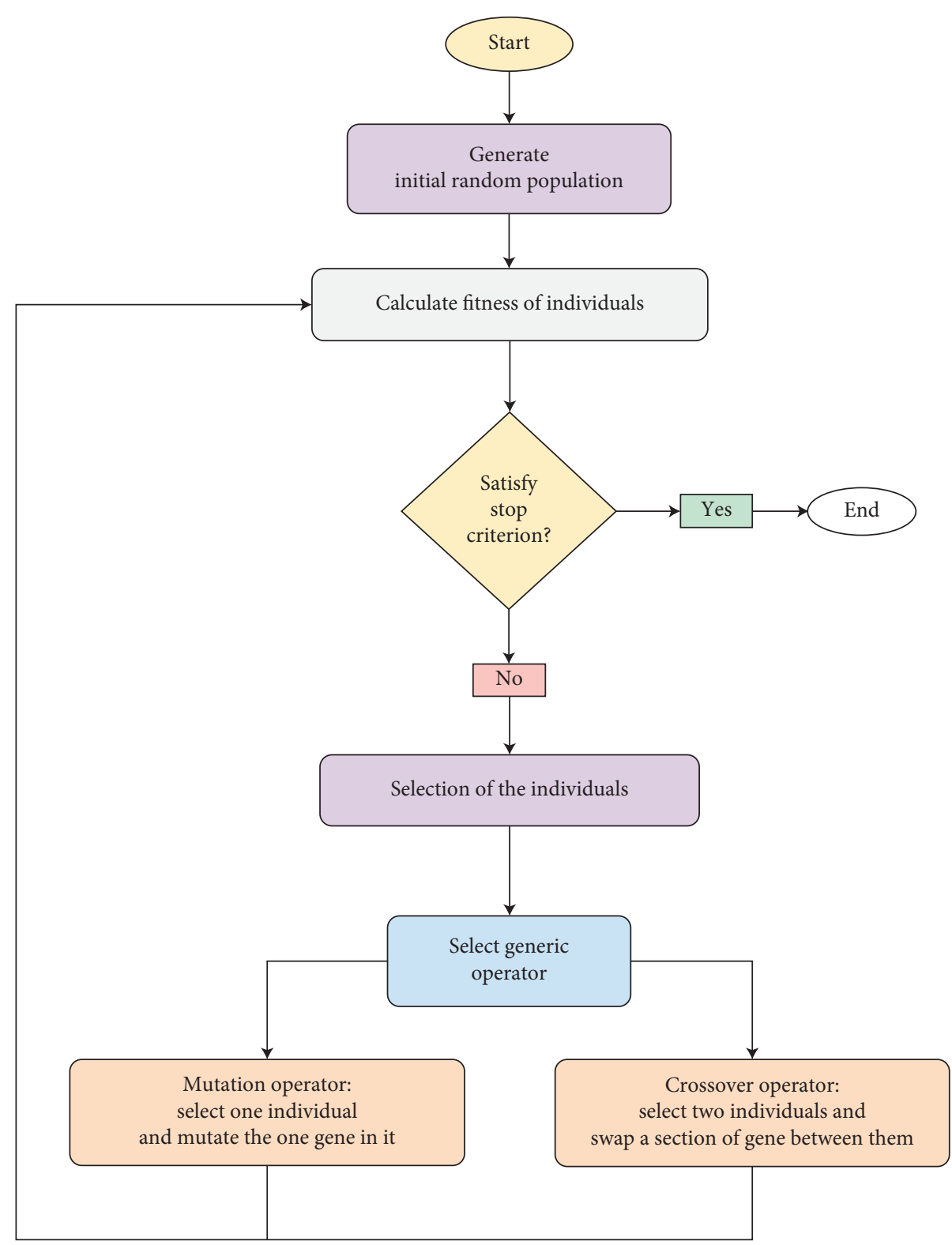

FIgURE 1: Flowchart of genetic algorithm [28].

\section{Creating the Databank}

3.1. Design and Analysis of Nonlinear Models. This study is based on 2-D regular frames with a constant height of 3 meters and 5 meters' bays. The columns are pinned connected to the base and capable of conveying the moment forces along with their height. The beams are also pinned linked to the columns. Dead and live uniform loads on beams are 2500 and $1000 \mathrm{~kg} / \mathrm{m}$, respectively. Furthermore, the yield stress of steels is considered $2400 \mathrm{~kg} / \mathrm{cm}^{2}$. The number of stories, $n_{s}$, is considered to be $3,6,9,12,15$, and 20 . The characteristic configuration of $2-\mathrm{D}$ frames is illustrated in Figure 2. The basic period of the frames is calculated by using the relation $T=0.08 \mathrm{H}^{0.75}$ and considering $\mathrm{H}$ as the total height of the frames [30]. Links have been categorized into short, intermediate, and long length, similar to the ones specified in earlier studies [31-33]. The link behavior is controlled by shear for values less than $1.6\left(M_{P} / V_{P}\right)$ (where $M_{P}$ and $V_{P}$ represent the plastic moments and the plastic shear strengths, respectively), while it is controlled by flexure for values greater than 2.6 $\left(M_{P} / V_{P}\right)$. A combination of shear and flexural yielding occurs for link lengths between 1.6 $\left(M_{P} / V_{P}\right)$ and 2.6 $\left(M_{P} / V_{P}\right)$, [34]. Hence, models have been developed for these triple link beam length ratios $(\xi=e / L), 0.2,0.35$, and 0.50 .

Moreover, each model has been expanded with brace slenderness, $\lambda$, in triple level. The slenderness of braces is obtained using the following equation [12]:

$$
\lambda=\frac{l}{\pi \cdot r} \sqrt{\frac{F_{y}}{E}},
$$




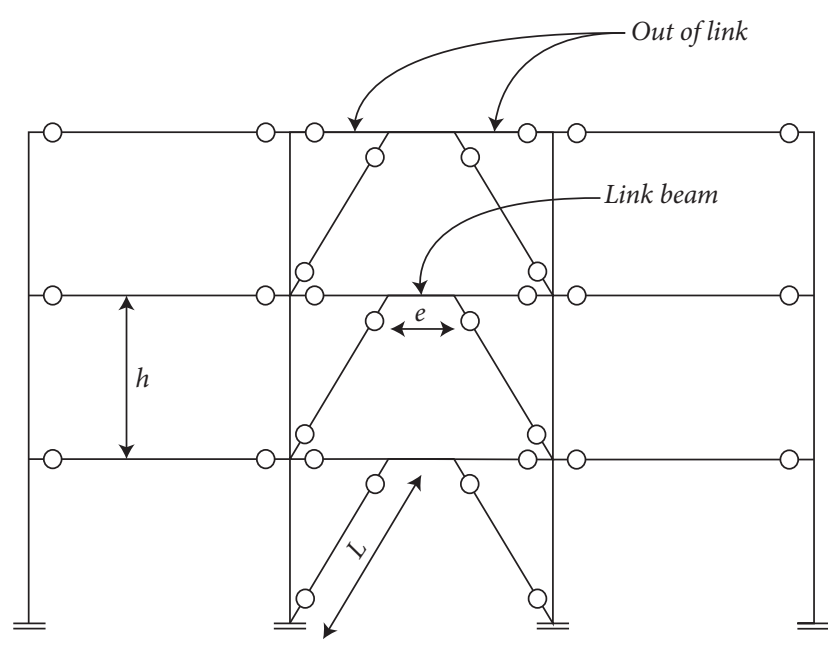

Figure 2: Typical configuration of EBFs.

where $l$ represents the length of the braces, $r$ denotes the gyration radius of the bracing section, $F_{y}$ represents the applied yielding stress of the steel, and $E$ denotes Young's modulus of materials.

The effect of the columns' stiffness is given by a coefficient, $\alpha$, as calculated by the following equation [12]:

$$
\alpha=\frac{n_{c} \cdot I_{c} \cdot L_{d}}{n_{d} \cdot A_{d} \cdot h^{3} \cdot \cos ^{2} \theta},
$$

where $n_{c}$ and $n_{d}$ indicate the number of columns and braces in a story, respectively, $I_{c}$ represents the second moment of inertia of the columns, $h$ denotes the floor height, and $\theta$ indicates the angle between the brace and the beam.

Diagonal braces, columns, and beam segments in link outside are modeled to stay basically elastic on the basis of capacity design concepts $[35,36]$. Such members, therefore, need to have sufficient strength to resist forces relative to the link expected strength, such as strain hardening [37]. The braces are developed in order to have adequate resistance because of seismic loading equal to forces created by adjusted link shear strength. The beam design outside the link is like the brace. The columns are adapted for resisting the forces made by the adjusted shear strength of all links above the column level.

The EBFs have been designed under AISC 360-10 [34] using ETABS 2016 [38] software. Accordingly, a database family of models is produced at $6\left(n_{s}\right) * 3(\alpha) * 3(\lambda) * 3(\xi)=$ 162 members. In the following, all EBFs have extended with 4 various rotation angles of link beams values, in accordance with the 4 performance levels. The first performance level is related to forming the first plastic hinge in the link beam, and the rest of the performance levels taken from ASCE41-13 [39] corresponded to the angle of rotation of the link beam. Using Equation $\Delta_{i}=\left(\gamma_{i} e h / L\right)$, for the quadruple performance levels extracted from ASCE41-13 [39] for the different link beam lengths, the maximum displacement is related to the link beam rotation. $\Delta_{i}, \gamma_{i}, e, h$, and $L$ are displacement, link beam rotation, link beam length, story height, and brace length, respectively. Moreover, extended
EBFs are analyzed under 20 pulse-like near-fault earthquakes. For the nonlinear time-history analyses, OpenSEES [40] software has been used.

Importance of link models in the assessment of the seismic response of multi-storey EBFs designed by EC8 [1] has been examined in the Bosco et al. study [41]. The link beam inelastic response, in EBFs, has been modeled using the method suggested by Bosco et al. [42]. The flexural bending and shear force effect is simulated by the model on the link beams' inelastic behavior with short, intermediate, as well as long length. The link model consists of five elements joined in series, as illustrated in Figure 3. The middle element (EL0) has the same length and moment of link inertia, allowing its flexural elastic response to be reflected. In this simulation, two zero-length elements (EL1 and EL2) exist. The elastic and inelastic shear response of half a link is taken into account by EL1, while the inelastic flexural response of the ending part of the link is taken into account by EL2. Independent relative vertical displacements and relative rotations are allowed in the nodes EL1 and EL2, respectively [42]. With the help of elastic elements, beams, columns, braces, and beam segments outside the links are modeled to remain elastic basically. In the analyses, the Rayleigh damping is regarded. In order that the frame first and third modes are defined by an equivalent viscous damping factor of 0.05 , stiffness and mass coefficients are determined.

3.2. Near-Fault Records. Near-fault earthquakes are selected based on the classification presented in Baker's study [43]. The features of the chosen earthquakes are presented in Table 1. As a result, the final database will be $162 * 4 * 20=12960$.

In order to produce the expected database, 12960 timehistory analyses are performed based on an IDA analysis platform using OpenSEES [40] software. In this regard, a single accelerometer is repeatedly affected by multiplying the accelerometer in a scale-factor (SF) coefficient. Corresponding to the performance levels, the maximum interstory drift of the frame is compared to the target values of ASCE4113 [39] in each iteration. The repeat operation continues until the expected values are reached and then stops [14]. The appropriate coefficient for different performance levels is calculated using the Bayesian method. This process is performed for a specific performance level based on the flowchart shown in Figure 4 for a single earthquake [14].

Researchers have been criticized for scaling, especially when they are above 10 or even $12[44,45]$, because the results within the range of normal earthquakes have led to the elimination of some of the data that claims higher than 12 from the databank. This screening eventually results in the use of a 9026 net databank from 12960 data. For each data, the maximum roof displacement, $u_{r \text { max }}$ and interstory drift, $\mathrm{IDR}_{\max }$, are calculated.

3.3. Verification. Modelling validation is one of the most important and fundamental steps in any study. This is especially important for analytical studies that require a large 


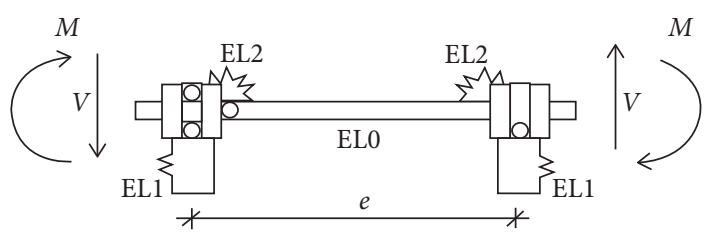

Figure 3: Modelling of the link [42].

TABLE 1: Characteristics of near-fault earthquakes used in the study.

\begin{tabular}{|c|c|c|c|c|c|c|}
\hline Record no. & Earthquake name & Year & Station name & $\mathrm{PGA}^{\mathrm{a}}(\mathrm{g})$ & $\mathrm{Mw}^{\mathrm{b}}$ & $\mathrm{R}^{\mathrm{c}}(\mathrm{km})$ \\
\hline 1 & Imperial Valley-06 & 1979 & EC County Center FF & 0.179721 & 6.53 & 7.31 \\
\hline 2 & Imperial Valley-06 & 1979 & El Centro Array \#7 & 0.462394 & 6.53 & 0.56 \\
\hline 3 & Imperial Valley-06 & 1979 & El Centro Array \#8 & 0.467966 & 6.53 & 3.86 \\
\hline 4 & Imperial Valley-06 & 1979 & El Centro Differential Array & 0.417229 & 6.53 & 5.09 \\
\hline 5 & Morgan Hill & 1984 & Coyote Lake Dam (SW Abut) & 0.813971 & 6.19 & 0.53 \\
\hline 6 & Loma Prieta & 1989 & LGPC & 0.943935 & 6.93 & 3.88 \\
\hline 7 & Landers & 1992 & Lucerne & 0.704174 & 7.28 & 2.19 \\
\hline 8 & Landers & 1992 & Yermo Fire Station & 0.235782 & 7.28 & 23.62 \\
\hline 9 & Northridge-01 & 1994 & Jensen Filter Plant & 0.517814 & 6.69 & 5.43 \\
\hline 10 & Northridge-01 & 1994 & Newhall-Fire Station & 0.723597 & 6.69 & 5.92 \\
\hline 11 & Northridge-01 & 1994 & Rinaldi Receiving Station & 0.869806 & 6.69 & 6.50 \\
\hline 12 & Northridge-01 & 1994 & Sylmar-Converter Station & 0.594294 & 6.69 & 5.35 \\
\hline 13 & Northridge-01 & 1994 & Sylmar-Converter Station East & 0.828472 & 6.69 & 5.19 \\
\hline 14 & Northridge-01 & 1994 & Sylmar-Olive View Med FF & 0.732606 & 6.69 & 5.30 \\
\hline 15 & Kobe, Japan & 1995 & KJMA & 0.854262 & 6.90 & 0.96 \\
\hline 16 & Kobe, Japan & 1995 & Takarazuka & 0.645232 & 6.90 & 0.27 \\
\hline 17 & Kocaeli, Turkey & 1999 & Gebze & 0.241333 & 7.51 & 10.92 \\
\hline 18 & Chi-Chi, Taiwan & 1999 & TCU049 & 0.286217 & 7.62 & 3.78 \\
\hline 19 & Chi-Chi, Taiwan & 1999 & TCU053 & 0.224488 & 7.62 & 5.97 \\
\hline 20 & Chi-Chi, Taiwan & 1999 & TCU068 & 0.564477 & 7.62 & 0.32 \\
\hline
\end{tabular}

${ }^{a}$ Peak ground acceleration. ${ }^{b}$ Moment magnitude. ${ }^{c}$ Closest distance from the recording site to the ruptured area.

database. It is clear that if modeling assumptions have errors, the results applied in empirical extensions will also be inaccurate. Therefore, for validation, a 6-story structural model has been developed from the study of Fakhroddini et al. [37]. The frame is schematically similar to that shown in Figure 2. Also, 144 and 360 in show the uniform story height and bay length, respectively. Considering $L$ as the length of the beam, three different values, $0.1,0.3$, and 0.5 , have been taken as $a$ to create three different link beam values. These link beam lengths have been categorized into short, intermediate, and long lengths, similar to ones shown in the earlier studies [31-33]. The link behavior is controlled by shear for values less than $1.6\left(M_{P} / V_{P}\right)$ (where $M_{P}$ and $V_{P}$ represent the plastic moments and the plastic shear strengths, respectively), while it is controlled by flexure for values greater than $2.6\left(M_{P} / V_{P}\right)$. A combination of shear and flexural yielding occurs for link lengths between 1.6 $\left(M_{P} / V_{P}\right)$ and 2.6 $\left(M_{P} / V_{P}\right)$ [34]. All frames include three bays with simple beam-to-column connections. All beams' uniform dead and live loads are 0.12 and $0.06 \mathrm{kips} / \mathrm{in}$, respectively; all frames' seismic floor masses are regarded as 206 kips. A steel grade of A992 with a yield strength of $50 \mathrm{ksi}$ is applied in designing all structural members. The final section sizes of frames are summarized in Table 2. The EBFs provided in Table 2 are analyzed in order to define their response to the 15 seismic excitations. For the nonlinear time-history analyses, OpenSEES software is used. The link beam inelastic response is modeled using the method suggested by Bosco et al. (2015) [42]. For every ground motion, the scale factor (SF) of the ground motion, related to life safe (LS) performance level, is defined via incremental dynamic analysis (IDA) on the basis of acceptance criteria of ASCE 41-13 [39]. As a final point, the median peak floor displacements are recorded vs the responses from the OpenSEES shown in Figure 5. In this study, the comparison of the diagrams presented attests to the adequate accuracy of the modeling phase.

\section{Using GA to Develop the New Correlation}

Different parameters were selected for this study. Considering the procedure explained in previous section, 12960 data were calculated and used. The selected data were divided into two groups: one group including 6769 data sets used as training data for developing the correlation and the rest of 2257 data sets used as test data for verify the correlation validation. The training and test data were selected randomly. The data consist of the number of stories, beam link length to the beam length ratio, braces slenderness, stiffness of columns, fundamental period of structure, roof ductility, and behavior factor within the ranges as shown in Table 3. 


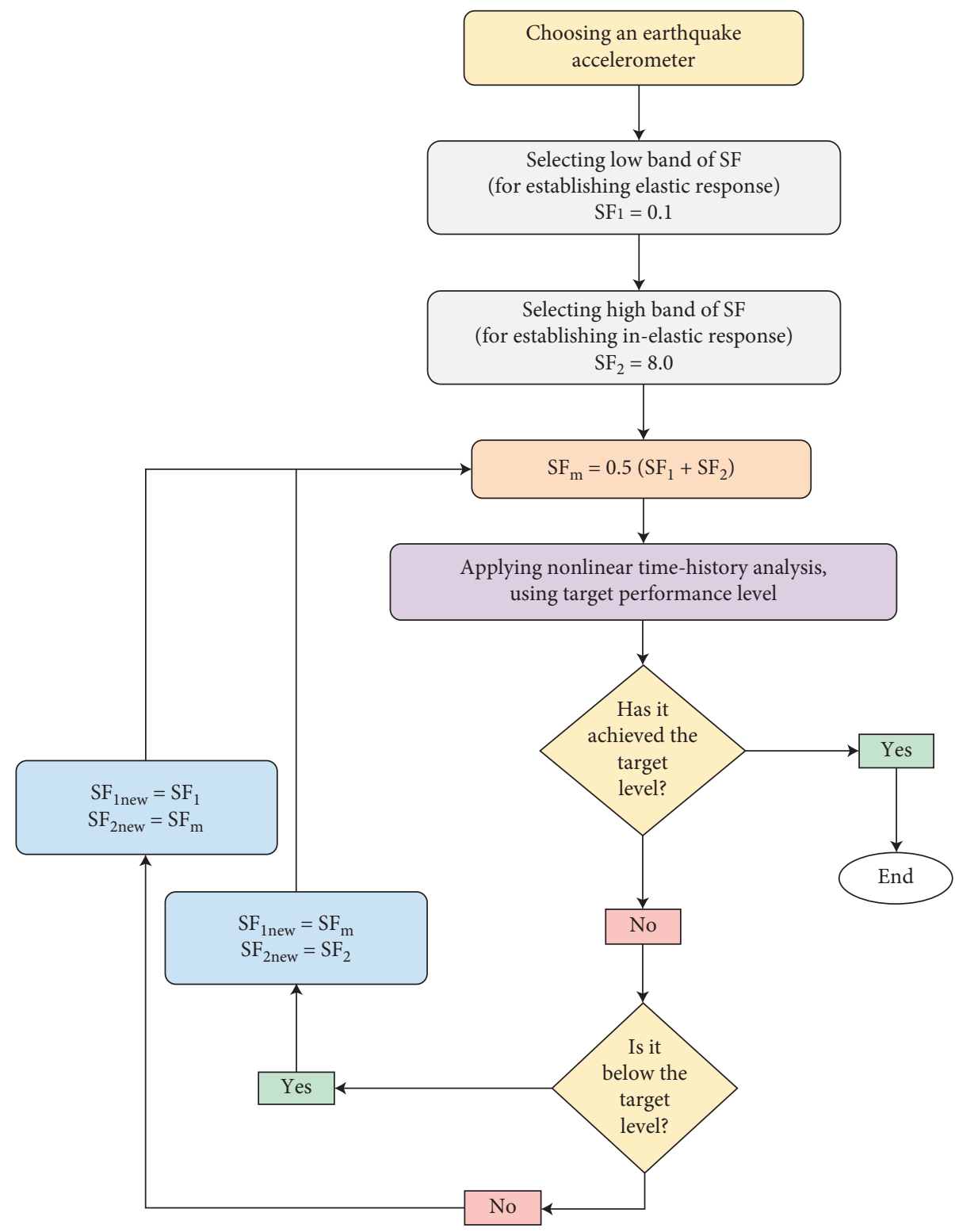

Figure 4: Flowchart of the change in scale factor.

TABLe 2: Section sizes of the 6St-EBFs by Fakhroddini et al. [37].

\begin{tabular}{|c|c|c|c|c|c|}
\hline $\begin{array}{l}\text { Link length } \\
a=(e / L)\end{array}$ & Side columns & Middle columns & Link beam & $\begin{array}{c}\text { Gravity } \\
\text { beams }\end{array}$ & Brace \\
\hline 0.1 & $3(14 \times 38)+3(14 \times 38)$ & $3(14 \times 311)+3(14 \times 132)$ & $2(14 \times 53)+3(14 \times 48)$ & $14 \times 109$ & $5(6 \times 1 / 2)+6 \times 1 / 4$ \\
\hline 0.3 & $3(14 \times 38)+3(14 \times 30)$ & $3(14 \times 311)+3(14 \times 132)$ & $4(14 \times 68)+2(14 \times 48)$ & $14 \times 109$ & $\begin{array}{c}3(6 \times 1 / \\
2)+3(6 \times 1 / 4)\end{array}$ \\
\hline 0.5 & $3(14 \times 38)+3(14 \times 30)$ & $3(14 \times 426)+3(14 \times 176)$ & $2(14 \times 132)+4(14 \times 68)$ & $14 \times 109$ & $\begin{array}{c}4(6 \times 1 / 2)+2 \\
(6 \times 1 / 4)\end{array}$ \\
\hline
\end{tabular}

Several cases were examined by the previous researchers $[12,46]$ to find an appropriate correlation between these parameters for $q$ prediction. After several regressive examinations, they found that there is a powerful relationship between the independent parameters, number of stories $\left(n_{s}\right)$, brace slenderness $(\lambda)$, stiffness of columns $(\alpha)$, fundamental period of structure $\left(T_{p}\right)$, roof ductility $\left(\mu_{R}\right)$, and $(q)$ for CBF steel frames under regular earthquakes as shown as follows:

$$
q=1+p_{1} \cdot\left(\mu_{R}-1\right)^{p_{2}} \cdot f\left(n_{s}, \lambda, \alpha, \frac{T}{T_{p}}\right) .
$$




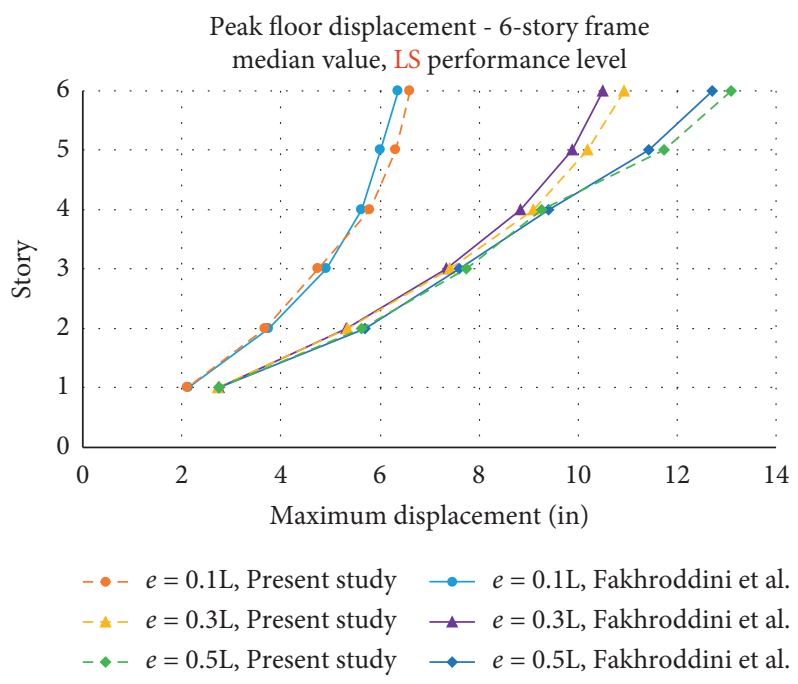

FIgURE 5: Model validation comparison with the result of Fakhroddini et al. [37].

TABLE 3: Range of the data used.

\begin{tabular}{lccccc}
\hline \multirow{2}{*}{ Parameter } & \multicolumn{2}{c}{ Number of data } & \multicolumn{2}{c}{ Range of data } & \multicolumn{2}{c}{ Mean data } \\
& Training data & Test data & Training data & Test data & Training data \\
\hline$n_{s}$ & 6769 & 2257 & $3-20$ & $3-20$ & 11.7959 \\
$\xi$ & 6769 & 2257 & $0.2-0.5$ & $0.2-0.5$ & 0.34386 \\
$\lambda$ & 6769 & 2257 & $0.22135-0.82729$ & $0.22135-0.82729$ & 0.39832 \\
$\alpha$ & 6769 & 2257 & $0.00362-0.06122$ & $0.00362-0.06122$ & 0.01540 \\
$T_{p}$ & 6769 & 2257 & $0.952-12.845$ & $0.952-12.845$ & 5.06167 \\
$\mu_{R}$ & 6769 & 2257 & $0.35908-11.9994$ & $0.46211-11.9818$ & 3.81001 \\
$q$ & 6769 & 2257 & $1-11.979$ & $1-16.8088$ & 0.398381 \\
\hline
\end{tabular}

To account the effect of link beam length, $\xi$, is considered as an extra parameter to the function. Moreover, due to the properties of near-fault earthquakes, parameter $\left(T / T_{p}\right)$ changes to $T_{p}$. Therefore, basic platform of the equation will change to equation (4); in other words,

$$
q=1+p_{1} \cdot\left(\mu_{R}-1\right)^{p_{2}} \cdot f\left(n_{s}, \lambda, \alpha, T_{p}, \xi\right) .
$$

Equation (4) could be rewritten as equation (5) to be clearer:

$$
q=1+p_{1} \cdot\left(\mu_{R}-1\right)^{p_{2}} \cdot n_{s}^{p_{3}} \cdot \lambda^{p_{4}} \cdot \alpha^{p_{5}} \cdot T_{p}^{p^{p_{6}}} \cdot \xi^{p_{7}} .
$$

The roof ductility, $\mu_{R}$, is obtained by dividing the inelastic roof displacement, $\Delta_{i}$, by the yielding displacement, $\Delta_{y}$, obtained by nonlinear time-history and pushover analyses, respectively.
The relationship accuracy of equation (5) depends on constants $p_{1}$ to $p_{7}$. These coefficients should be determined so that the difference between the predicted $q\left(q_{\text {predicted }}\right)$ and the real $q\left(q_{\text {real }}\right)$ is minimized. For constructing an appropriate correlation, the training data sets were used. The relationship between the independent parameters $\left(n_{s}, \lambda, \alpha, T_{p}\right.$, and $\left.\mu_{R}\right)$ and $q$ has been shown in Figures 6 and 7 based on training and testing data, respectively.

It is obvious that the accuracy of correlation of equation (5) will be maximized if the constants $p 1$ through $p 7$ are optimal. To determine the constants $p 1$ through $p 7$ optimally, GA was applied. The objective function of GA (fitness function) is the function that must be optimized. To determine the constants $p_{1}$ to $p_{7}$ using GA, the fitness function is defined as follows:

fitness function $=$ mean-squared error $(\mathrm{MSE})$

$$
\begin{aligned}
& =\sum_{i=1}^{n}\left(\left[q_{\text {real }}-q_{\text {predicted }}\right]^{2} /(n-p)\right), \\
& =\sum_{i=1}^{n}\left(\left[q_{\text {real }}-\left(1+p_{1} \cdot\left(\mu_{R}-1\right)^{p_{2}} \cdot n_{s}^{p_{3}} \cdot \lambda^{p_{4}} \cdot \alpha^{p_{5}} \cdot T_{p}^{p_{6}} \cdot \xi^{p_{7}}\right)\right]^{2} /(n-p)\right) .
\end{aligned}
$$




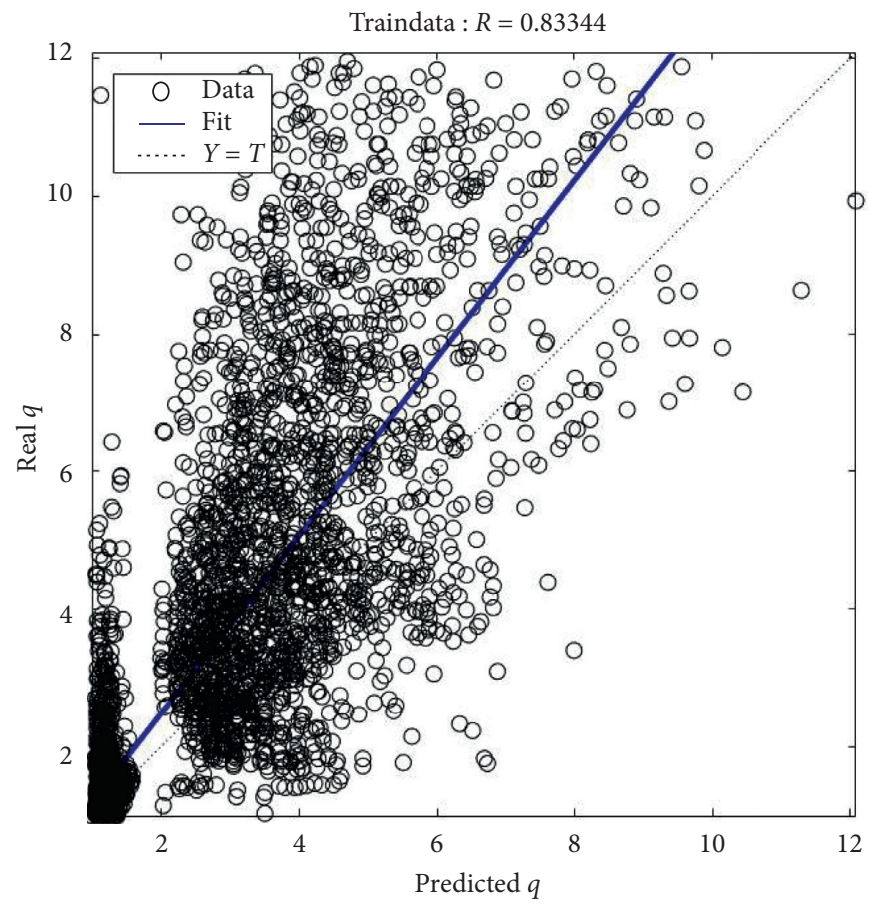

Figure 6: Relationship between the independent parameters $\left(n_{s}, \lambda, \alpha, T_{p}\right.$, and $\left.\mu_{R}\right)$ and predicted $q$ (training data).

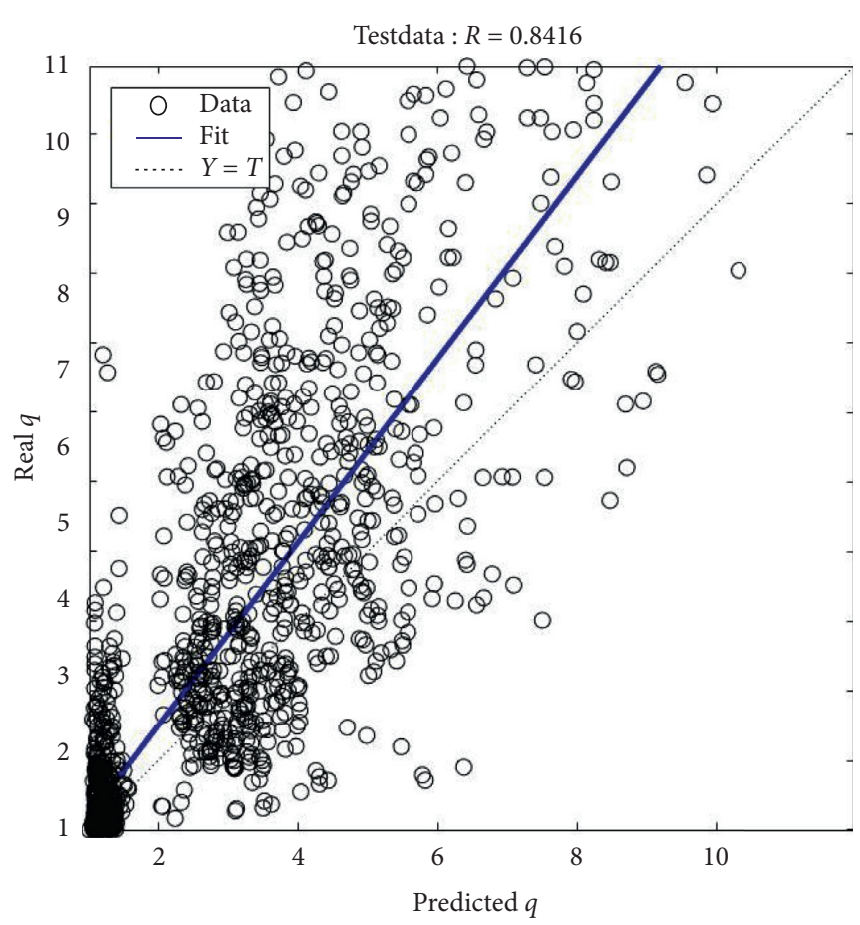

FIgURE 7: The correlation between independent parameters $\left(n_{s}, \lambda, \alpha, T_{p}\right.$, and $\left.\mu_{R}\right)$ and predicted $q$ values from equation (5) (test data).

where $n$ is the number of the used data and $p_{1}$ to $p_{7}$ are the constants which are predicted by the GA. Parameters used to perform genetic algorithm are listed in Table 4 . The constants $p_{1}$ to $p_{7}$ were defined as vectors in order to accelerate the algorithm performance. In this case, the fitness function is called once instead of being called for each member and, therefore, its performance accelerates. The "fminsearch," which is a hybrid function, was used to improve the results obtained from the GA. After the end of the GA, the "fminsearch" which is an optimizer function uses genetic algorithm end point as its own starting point and is executed. This function improves the results. Training data were used to determine the constants $p 1$ through $p 7$ as inputs of GA. After adjusting the algorithm, the final results are listed in Table 5.

Figure 8 shows the real and predicted $q$ from predicted correlation in the training data. For the verification of the proposed correlation, test data including 2257 data sets were used. Figure 9 shows the real and predicted $q$ from the proposed correlation (based on the constants $p 1$ through $p 7$ which are listed in Table 4) in the test data. According to the results presented in Figure 9, it seems that there is an acceptable agreement between predicted $q$ values from the proposed correlation and the real $q$ values.

\section{Use of the Purposed Correlation: A Simple Design Example}

This section aims to evaluate the ability of correlation in predicting of seismic demand parameters (SDPs). For this purpose, a 5 -story structure having a plan of 12 by 12 square meters and 3 bays in each side, each with a length of 4 meters, is considered. The story floors are equal to $3.20 \mathrm{~m}$, and the height of the floor is regularly considered. Thus, the total height of the structure will be $5 * 3.20=16.00 \mathrm{~m}$. The structural seismic system is the eccentrically braced steel frame. The beam-to-column connections are pinned. For beam, column, and brace sections, IPE, HEB, and TUBO 
TABLE 4: Parameters used in the GA for predicting $q$.

\begin{tabular}{lc}
\hline GA parameter & GA parameter that used for predicting $q$ \\
\hline Population & Population type: double vector; population size: $55 ;$ initial range: [0; 1$]$ \\
Fitness scaling & Scaling function: rank \\
Selection & Selection function: roulette \\
Reproduction & Elite count: 3 ; crossover fraction: 0.85 \\
Mutation & Mutation function: Gaussian; shrink value: $1 ;$ scale: 0.1 \\
Crossover & Crossover function: scattered \\
Migration & Direction: forward; fraction: 0.8 ; interval: 40 \\
Hybrid function & Hybrid function: fminsearch \\
Algorithm setting & Initial penalty: 100; penalty factor: 980 \\
Stopping criteria & Generation: $1000 ;$ time limit: inf; fitness limit: inf; stall generation: $1000 ;$ stall time limit: inf \\
\hline
\end{tabular}

TABLE 5: The final proposed correlation and its constants.

\begin{tabular}{lc}
\hline Constant & $q=1+p_{1} \cdot\left(\mu_{R}-1\right)^{p_{2}} \cdot n_{s} p_{3} \cdot \lambda^{p_{4}} \cdot \alpha^{p_{5}} \cdot T_{p}^{p_{6}} \cdot \xi^{p_{7}}$ \\
\hline$p_{1}$ & 0.561349689 \\
$p_{2}$ & 1.3968 \\
$p_{3}$ & 0.378876627 \\
$p_{4}$ & -0.566266172 \\
$p_{5}$ & 0.145324743 \\
$p_{6}$ & -0.447411206 \\
$p_{7}$ & -0.130890499 \\
\hline
\end{tabular}

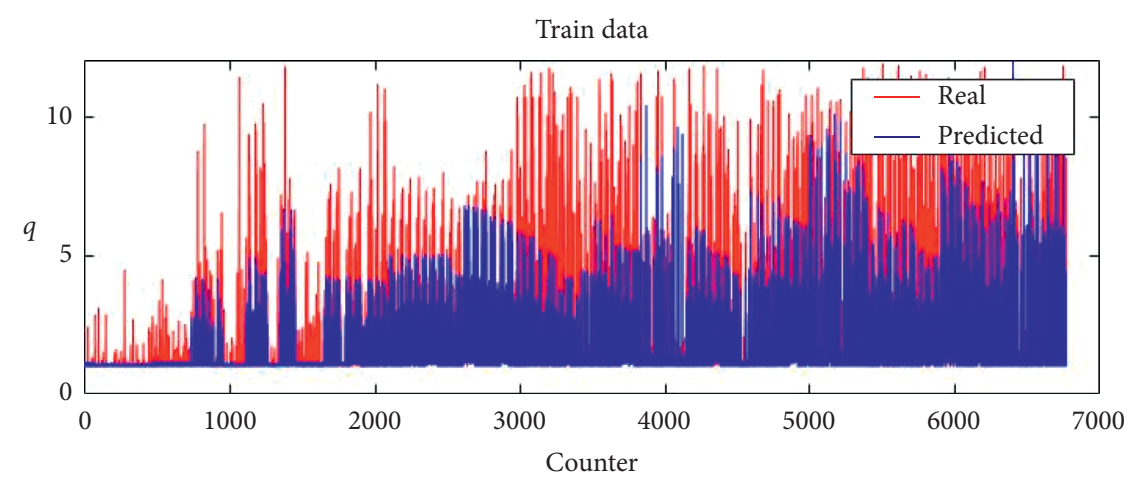

Figure 8: Real and predicted $q$ from predicted correlation (training data).

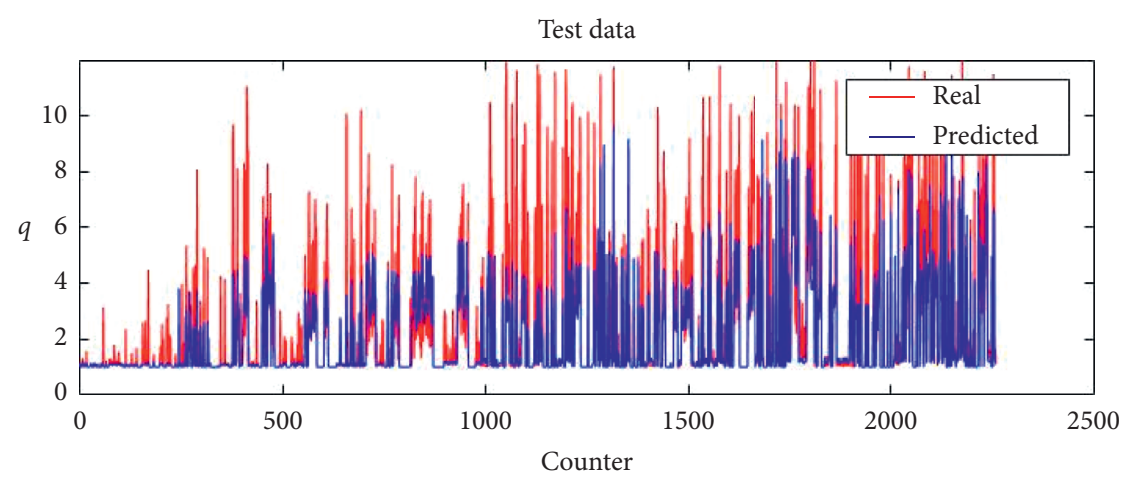

FIGURE 9: Real and predicted $q$ from predicted correlation (based on the constants $p 1$ through $p 7$ which are listed in Table 3) (test data).

sections were used, respectively, with a yield stress of $3700 \mathrm{~kg} / \mathrm{cm}^{2}$. Dead and live surface loads are considered 500 and $250 \mathrm{~kg} / \mathrm{m}^{2}$, respectively. Thus, considering the tributary width of $4 \mathrm{~m}$, the dead and live linear load are 1000 and
$500 \mathrm{~kg} / \mathrm{m}$, respectively, on the perimeter frames. The structure was designed based on the standard 2800 [30] with PGA of $0.30 \mathrm{~g}$ and type 2 soil. Based on the seismic live load contribution coefficients in Standard 2800 [30], the D + 0.2 L 
seismic load combination was used to calculate the seismic load of the frame. The structure was designed using the LRFD (load and resistance design method) method using ETABS software. For this purpose, the behavior factor, $q=7$, is selected according to standard 2800 [30]. IPE300, HEB240, and D193.7 $\times 5$ were found for beams, columns, and braces, respectively. Maximum roof displacement and maximum interstory drift ratio under reduced spectrum (divided by q) are 0.0452 and $0.0019 \mathrm{~m}$, respectively. Therefore, the maximum inelastic roof displacement equals

$$
\text { Disp }_{\max , \text { Roof }}^{\text {in.el. }}=q \times \text { Disp }_{\max , \text { Roof }}^{\text {el }}=7 \times 0.0452=0.3164 \mathrm{~m} \text {. }
$$

Also, the maximum inelastic interstory drift is

$$
\mathrm{IDR}_{\max }^{\text {in.el. }}=q \times \mathrm{IDR}_{\max }^{\mathrm{el}}=7 \times 0.0019=0.0133 \text {. }
$$

The geometrical values of the studied frame properties are also calculated from the relationships below. Thus the slenderness coefficient of the braces is equal to

$$
\lambda=\frac{l}{\pi \cdot r} \sqrt{\frac{F_{y}}{E}}=0.9689 .
$$

And, the effect of the columns stiffness is calculated as follows:

$$
\alpha=\frac{n_{c} \cdot I_{c} \cdot L_{d}}{n_{d} \cdot A_{d} \cdot h^{3} \cdot \cos ^{2} \theta}=0.0299 .
$$

The fundamental period of the structure is equal to $T=0.64 \mathrm{~s}$, according to the 2800 standard [30]. Having the abovementioned geometrical parameters and using the proposed correlation, maximum roof ductility is calculated $\mu_{R}=2.8802$. Thus, the maximum inelastic roof displacement is

$$
\text { Disp } \text { max.Roof }_{\text {in.el. }}^{\text {Rof }}=\mu_{R} \times \text { Disp }_{\max , \text { Roof }}^{\text {el }}=2.8802 \times 0.0452=0.1301 \mathrm{~m} \text {. }
$$

On the other hand, corresponding values can be obtained, using nonlinear time-history analysis under nearfault earthquakes and mean value of analysis results:

$$
u_{r \max }^{\mathrm{NTHA}}=0.13854 \mathrm{~m} \text {. }
$$

The slight discrepancy between the results of the proposed correlation and the respond of the time-history analysis indicates that the proposed correlation is in good agreement.

\section{Conclusion}

As a result, after studying a considerable number of EBF frames, a nonlinear dynamic analysis of a large database was prepared. The genetic algorithm (GA), which is one of the most powerful techniques of the artificial intelligence in optimization, has been used to develop the correlation. As suggested by simple relationships, it is possible to obtain an acceptable estimate of seismic demand parameters without the need for complex analysis. The main emphasis is on introducing the capability of the proposed relationship in adapting them to the framework of design methods based on elastic analysis. The new empirical relation is proposed to predict the behavior factor $q$ for EBF steel frames under the near-fault earthquakes. The proposed correlation is a nonlinear function of number of stories, braces slenderness, stiffness of columns, fundamental period of structure, link beam-to-beam length ratio, and roof ductility. To evaluate its accuracy, the mean-squared error (MSE) and correlation coefficient $(R)$ between predicted values from the proposed correlation and real values in the test data were calculated. The correlation coefficient in the test data was 0.8416 . Finally, a 5-storey steel frame with force factor 7 (2800 standard, Rev 4 for EBF frames) was designed and analyzed using nonlinear time history against acceleration of the present paper to evaluate the robustness of the proposed relationship in estimating the nonlinear displacement of the structure. Then, roof ductility was calculated, and the corresponding roof nonlinear maximum displacement was calculated, using the purposed relationship between roof ductility and behavior factor. In the following, the mean value of nonlinear roof displacement obtained from nonlinear time-history analysis was compared with the maximum value of nonlinear roof displacement initialized using the proposed relationships in this paper. The results show the capability of the proposed relation in calculating the maximum inelastic roof displacement for structures was designed according to AISC 360-10 [34].

\section{Data Availability}

The data used to support the study are included within the article.

\section{Conflicts of Interest}

The authors declare that there are no conflicts of interest regarding the publication of this paper.

\section{References}

[1] B. Standard, "Eurocode 8: design of structures for earthquake resistance," Part, vol. 1, pp. 1998-2001, 2005.

[2] K. Shimazaki and M. A. Sozen, Seismic Drift of Reinforced Concrete Structures, Hazama-Gumi, Tokyo, Japan, 1984.

[3] A. Lepage, A Method for Drift-Control in Earthquake-Resistant Design of RC Building Structures, University of Illinois at Urbana-Champaign, Champaign, IL, USA, 1997.

[4] A. Gupta and H. Krawinkler, "Behavior of ductile SMRFs at various seismic hazard levels," Journal of Structural Engineering, vol. 126, no. 1, pp. 98-107, 2000.

[5] T. L. Karavasilis, N. Bazeos, and D. E. Beskos, "Estimation of seismic inelastic deformation demands in plane steel MRF with vertical mass irregularities," Engineering Structures, vol. 30, no. 11, pp. 3265-3275, 2008.

[6] T. L. Karavasilis, N. Makris, N. Bazeos, and D. E. Beskos, "Dimensional response analysis of multistory regular steel MRF subjected to pulselike earthquake ground motions," Journal of Structural Engineering, vol. 136, no. 8, pp. 921-932, 2010. 
[7] R. A. Medina and H. Krawinkler, Seismic Demands for Nondeteriorating Frame Structures and their Dependence on Ground Motions, Pacific Earthquake Engineering Research Center, Berkeley, CA, USA, 2004.

[8] R. A. Medina and H. Krawinkler, "Evaluation of drift demands for the seismic performance assessment of frames," Journal of Structural Engineering, vol. 131, no. 7, pp. 10031013, 2005.

[9] C. A. Castiglioni and A. Zambrano, "Determination of the behaviour factor of steel moment-resisting (MR) frames by a damage accumulation approach," Journal of Constructional Steel Research, vol. 66, no. 5, pp. 723-735, 2010.

[10] A. T. Council, Improvement of Nonlinear Static Seismic Analysis Procedures, FEMA Region II, New York, NY, USA, 2005.

[11] T. L. Karavasilis, N. Bazeos, and D. E. Beskos, "Drift and ductility estimates in regular steel MRF subjected to ordinary ground motions: a design-oriented approach," Earthquake Spectra, vol. 24, no. 2, pp. 431-451, 2008.

[12] T. L. Karavasilis, N. Bazeos, and D. E. Beskos, "Estimation of seismic drift and ductility demands in planar regular X-braced steel frames," Earthquake Engineering \& Structural Dynamics, vol. 36, no. 15, pp. 2273-2289, 2007.

[13] A. I. Dimopoulos, N. Bazeos, and D. E. Beskos, "Seismic yield displacements of plane moment resisting and $x$-braced steel frames," Soil Dynamics and Earthquake Engineering, vol. 41, pp. 128-140, 2012.

[14] A. S. Tzimas, T. L. Karavasilis, N. Bazeos, and D. E. Beskos, "Extension of the hybrid force/displacement (HFD) seismic design method to 3D steel moment-resisting frame buildings," Engineering Structures, vol. 147, pp. 486-504, 2017.

[15] M. Gerami, N. Siahpolo, and R. Vahdani, "Effects of higher modes and MDOF on strength reduction factor of elastoplastic structures under far and near-fault ground motions," Ain Shams Engineering Journal, vol. 8, no. 2, pp. 127-143, 2017.

[16] P. R. Santa-Ana and E. Miranda, "Strength reduction factors for multi-degree-of-freedom systems," in Proceedings of the 12th world conference on Earthquake Engineering, vol. 1446, Auckland, New Zealand, January 2000.

[17] H. Krawinkler, J. Anderson, V. Bertero, W. Holmes, and C. Theil, "Steel buildings," Earthquake Spectra, vol. 12, no. S1, pp. 25-47, 1996.

[18] E. Kalkan and S. K. Kunnath, "Effects of fling step and forward directivity on seismic response of buildings," Earthquake Spectra, vol. 22, no. 2, pp. 367-390, 2006.

[19] M. Gerami and D. Abdollahzadeh, "Local and global effects of forward directivity," Građevinar, vol. 65, no. 11, pp. 971-985, 2013.

[20] A. H. Mashayekhi, M. Gerami, and N. Siahpolo, "Assessment of higher modes effects on steel moment resisting structures under near-fault earthquakes with forward directivity effect along strike-parallel and strike-normal components," International Journal of Steel Structures, vol. 19, no. 5, pp. 15431559, 2019.

[21] M.-B. Prendes-Gero, A. Bello-García, A. Bello-García, J.-J. del Coz-Díaz, F.-J. Suárez-Domínguez, and P.-J. G. Nieto, "Optimization of steel structures with one genetic algorithm according to three international building codes," Revista De La Construcción, vol. 17, no. 1, pp. 47-59, 2018.

[22] Matlab, The Language of Technical Computing, The MathWorks, Inc, Natick, MA, USA, 2012.

[23] A. Ede, O. Oshokoya, J. Oluwafemi, S. Oyebisi, and O. Olofinnade, "Structural analysis of a genetic algorithm optimized steel truss structure according to BS 5950," International Journal of Civil Engineering and Technology, vol. 9, no. 8, pp. 358-364, 2018.

[24] M. R. Baradaran and M. Madhkhan, "Application of an improved genetic algorithm for optimal design of planar steel frames," Periodica Polytechnica Civil Engineering, vol. 63, no. 1, pp. 141-151, 2019.

[25] J. Akbari and M. S. Ayubirad, "Seismic optimum design of steel structures using gradient-based and genetic algorithm methods," International Journal of Civil Engineering, vol. 15, no. 2, pp. 135-148, 2017.

[26] J. H. Holland, Adaptation in Natural and Artificial Systems: An Introductory Analysis with Applications to Biology, Control, and Artificial Intelligence, MIT Press, Cambridge, MA, USA, 1992.

[27] M. Mitchell, An Introduction to Genetic Algorithms, MIT Press, Cambridge, MA, USA, 1998.

[28] M. N. Ab Wahab, S. Nefti-Meziani, and A. Atyabi, "A comprehensive review of swarm optimization algorithms," PLoS One, vol. 10, no. 5, 2015.

[29] M. Karimnezhad, M. Heidarian, M. Kamari, and H. Jalalifar, "A new empirical correlation for estimating bubble point oil formation volume factor," Journal of Natural Gas Science and Engineering, vol. 18, pp. 329-335, 2014.

[30] Iranian Code of Practice for Seismic Resistant Design of Buildings, Vol. 3, Building and Housing Research Center (in Persian), Tehran, Iran, 2005.

[31] M. Bosco and P. P. Rossi, "Seismic behaviour of eccentrically braced frames," Engineering Structures, vol. 31, no. 3, pp. 664-674, 2009.

[32] A. Kuşyllmaz and C. Topkaya, "Design overstrength of steel eccentrically braced frames," International Journal of Steel Structures, vol. 13, no. 3, pp. 529-545, 2013.

[33] P. P. Rossi and A. Lombardo, "Influence of the link overstrength factor on the seismic behaviour of eccentrically braced frames," Journal of Constructional Steel Research, vol. 63, no. 11, pp. 1529-1545, 2007.

[34] A. Committee, Specification for Structural Steel Buildings (ANSI/AISC 360-10), American Institute of Steel Construction, Chicago, IL, USA, 2010.

[35] Kuşy, "Displacement amplification factors for steel eccentrically braced frames," Earthquake Engineering \& Structural Dynamics, vol. 44, no. 2, pp. 167-184, 2015.

[36] D. Özhendekci and N. Özhendekci, "Effects of the frame geometry on the weight and inelastic behaviour of eccentrically braced chevron steel frames," Journal of Constructional Steel Research, vol. 64, no. 3, pp. 326-343, 2008.

[37] A. Fakhraddini, S. Hamed, and M. J. Fadaee, "Peak displacement patterns for the performance-based seismic design of steel eccentrically braced frames," Earthquake Engineering and Engineering Vibration, vol. 18, no. 2, pp. 379-393, 2019.

[38] V. Etabs, Ultimate, Integrated Software for Structural Analysis \& Design, Computers and Structures Inc, Berkeley, CA, USA, 2016.

[39] R. Pekelnicky, S. D. Engineers, S. C. Poland, and N. D. Engineers, "ASCE 41-13: seismic evaluation and retrofit rehabilitation of existing buildings," in Proceedings of the SEAOC, Santa Fe, NM, USA, September 2012.

[40] F. McKenna, "OpenSees: a framework for earthquake engineering simulation," Computing in Science \& Engineering, vol. 13, no. 4, pp. 58-66, 2011.

[41] M. Bosco, A. Ghersi, E. M. Marino, and P. P. Rossi, "Importance of link models in the assessment of the seismic 
response of multi-storey EBFS designed by EC8," Ingegneria Sismica, vol. 33, no. 3, pp. 82-93, 2016.

[42] M. Bosco, E. M. Marino, and P. P. Rossi, "Modelling of steel link beams of short, intermediate or long length," Engineering Structures, vol. 84, pp. 406-418, 2015.

[43] J. W. Baker, "Quantitative classification of near-fault ground motions using wavelet analysis," Bulletin of the Seismological Society of America, vol. 97, no. 5, pp. 1486-1501, 2007.

[44] F. De Luca, I. Iervolino, and E. Cosenza, "Un-scaled, scaled, adjusted and artificial spectral matching accelerograms: displacement-and energy-based assessment," in Proceedings of XIII ANIDIS, L'Ingegneria Sismica in Italia, Bologna, Italy, January 2009.

[45] J. Hancock, The Influence of Duration and the Selection and Scaling of Accelerograms in Engineering Design and Assessment, Imperial College London (University of London), London, England, 2006.

[46] T. L. Karavasilis, N. Bazeos, and D. E. Beskos, "Seismic response of plane steel MRF with setbacks: estimation of inelastic deformation demands," Journal of Constructional Steel Research, vol. 64, no. 6, pp. 644-654, 2008. 